\title{
Allergic rhinitis patients associated with migraine: effect of treatment of allergic rhinitis on migrainous attack
}

\author{
Reham Farouk Zittoon ${ }^{1 *}$ (D), Dina Ibrahim Ahmed ${ }^{2}$, Nagy Michael Iskander ${ }^{1}$ and Yasser Taha Madian
}

\begin{abstract}
Background: Allergy immunology specialists frequently encounter with diagnosis of migraine headache; this is a prospective study to assess the ability of the treatment of allergic rhinitis in patients having migraine to decrease the attacks of migraine.

Results: Between June 2016 and Feb. 2019, 58 patients suffer from migraine and having positive allergic symptoms for all patients. CBC with differential, nasal smear and IgE test assessment of migraine disability assessment score, and complete otorhinology examination were done pretreatment and 3 months post treatment score to know the effect of the treatment of allergic rhinitis on the attack of migraine. The mean age of patients was 40 years old. Age distribution was between 18 and 59 years old. Sex was also distributed and found 21 males and 37 females, showing more presented in females. Hemoglobin was found between 10.8 and $12.4 \mathrm{mg} / \mathrm{dl}$, with mean $11.37 \mathrm{mg} / \mathrm{dl}$; IgE test was between 5 and $800 \mathrm{IU} / \mathrm{ml}$, with mean $171.29 \mathrm{IU} / \mathrm{ml}$; no patients were included in grade I while the majority were included in grade III. We noticed that patients improved from allergic rhinitis and migranous attack at the same time had $43.1 \%$ while patients improved allergic rhinitis but migraine became less frequent and less sever were $15.52 \%$ (partially improved). Patients improved allergic rhinitis. Grade I no pain showed statistically significant difference, also grade III moderate pain showed statistically significant difference. IgE level in improved cases around 88.4.
\end{abstract}

Conclusion: There is strong relation between migraine and allergic rhinitis; the use of intranasal corticosteroid sprays and oral antihistaminic for 3 months for treatment of migraine associated with allergic rhinitis which led to decrease in the prevalence and frequency.

Keywords: Migraine, Allergic rhinitis, Antihistamine, Intranasal corticosteroid

\section{Background}

Ear, nose, and throat (ENT) allergy immunology specialists frequently encounter with diagnosis of migraine headache in their patient according to high prevalence of migraine and allergic rhinitis in population [1].

Allergic rhinitis (AR), defined as an inflammatory condition of the nasal mucosa primarily mediated by an IgE-associated response to ubiquitous indoor and/or outdoor environmental allergens and characterized by

\footnotetext{
*Correspondence: dr.reham_zitttoon@outlook.com

${ }^{1}$ Suez Canal University Hospitals, 4.5 Km Ring Road, Ismailia, Egypt

Full list of author information is available at the end of the article
}

nasal pruritus, sneezing, rhinorrhea, and nasal congestion, in particular, is a very common chronic respiratory disorder that affects between 10 and 30\% (700 million people) of the world population $[2,3]$.

Migraine is a primary episodic headache disorder with various neurological complaints. Previous reports revealed that endogenous molecules such as calcitonin gene-related peptide, nitric oxide ( $\mathrm{NO})$, and histamine play an important role in the pathophysiology of migraine. However, the exact underlying mechanism is unclear [4-6].

\section{Springer Open}

(- The Author(s). 2021 Open Access This article is licensed under a Creative Commons Attribution 4.0 International License, which permits use, sharing, adaptation, distribution and reproduction in any medium or format, as long as you give appropriate credit to the original author(s) and the source, provide a link to the Creative Commons licence, and indicate if changes were made. The images or other third party material in this article are included in the article's Creative Commons licence, unless indicated otherwise in a credit line to the material. If material is not included in the article's Creative Commons licence and your intended use is not permitted by statutory regulation or exceeds the permitted use, you will need to obtain permission directly from the copyright holder. To view a copy of this licence, visit http://creativecommons.org/licenses/by/4.0/. 
There is a correlation between allergic rhinitis and migraine especially without aura; this correlation is more powerful and increased with increasing age [7].

The characteristic symptoms of allergic rhinitis are rhinorrhea, itching, sneezing fits, and nasal congestion and obstruction [8].

The goal of rhinitis treatment is to prevent or reduce the symptoms caused by the inflammation of affected tissues. Intranasal corticosteroids are the preferred treatment if medications are required, with other options used only if these are not effective. Mite-proof covers, air filters, and withholding certain foods in childhood do not have evidence supporting their effectiveness [9].

\section{Methods}

This is a prospective study to assess the effect of treatment of allergic rhinitis on migrainous attacks; between June 2016 and Feb. 2019, 58 patients suffer from migraine and having positive allergic symptoms.

Inclusion criteria include (1) patients referred to ENT clinic with migraine and having positive allergic symptoms (mouth breathing, itching, watery eye, nasal congestion, rhinorrhea, and confirmed by CBC with differential, nasal smear, and IgE test); (2) patients having migraine attack with assessment of migraine disability assessment (MIDAS) [10]; (3) age between (18:48) years old (to exclude hormonal effect in postmenopausal females); and (4) sex: both sexes are included.

Exclusion criteria include (1) patient known to have nasal polyp, deviated septum, or sinusitis; (2) other causes of headache such as stroke, cerebral palsy, trigeminal neuralgia, or hypertension; (3) patients with major illness; (4) patients that refuse to participate in this study; and (5) pregnant women.

Patients were diagnosed as allergic rhinitis by history of itching, watery eye, nasal congestion, rhinorrhea, and sneezing and confirmed by $\mathrm{CBC}$ with differential and immunoglobulin $\mathrm{E}$ test associated with migraine classified according to MIDAS. Then observed taking treatment of allergic rhinitis in the form of antihistamine and local steroid for at least 3 months, and re-evaluated by MIDAS score to know the effect of the treatment of allergic rhinitis on the attack of migraine.

The MIDAS contains the following: (1) days missed in work or school because of headaches, (2) days productivity at work or school reduced by half or more, (3) days household work not done because of headaches, (4) days productivity in household work reduced by half of more because of headaches, and (5) days family missed social activities because of headaches. The patient's score consists of the total of these five questions.

Score:

0 to 5 , MIDAS grade I, little or no disability
6 to 10 , MIDAS grade II, mild disability 11 to 20, MIDAS Grade III, Moderate disability $21+$, MIDAS grade IV, severe disability [10]

\section{Results}

All patients diagnosed as allergic rhinitis by history of itching, watery eye, nasal congestion, rhinorrhea, and sneezing and confirmed by CBC with differential and immunoglobulin E test (Table 1). All patients (58) did a complete otorhinology examination.

Those patients who had migraine characterized by headache lasting between 4 and $72 \mathrm{~h}$, unilateral location, aggravated with physical activity, with or without nausea were evaluated and classified according to the criteria of international headache society and frequency of migraine, with MIDAS [10].

After putting the patients that have allergic rhinitis with attacks of migraine on the MIDAS score, they were scored and then observed taking treatment of allergic rhinitis in the form of antihistamine and local steroid for at least 3 months, and re-evaluated by MIDAS score (Table 2) to know the effect of the treatment of allergic rhinitis on the attack of migraine.

Here, we made comparison of MIDA score before and after treatment among the studied patients to know the effect of treatment of allergic rhinitis on migranous attack (Table 3 and Fig. 1); we noticed that grade I no pain showed statistically significant difference, and also grade III moderate pain showed statistically significant difference.

We noticed here that IgE level in improved cases around 88.4 denote statistically significant difference within these group, whereas in not improved cases, there was statistically significant difference meaning high levels of IgE test in not improved cases.

Receiver operating characteristic curve (or ROC curve) (Fig. 2) analysis is a plot of the true positive rate against the false positive rate for the different possible cut points of a diagnostic test, which showed that area under the curve was $79 \%$, which means that the accuracy of the test is fair. The slope of the tangent line at a cut point gives the likelihood ratio (LR) for that graph shows ROC curves representing good test.

In our study, Rhino conjunctivitis Quality of Life Questionnaire [10] was done (Table 4) and there were significant improvements of patients regarding sleep problems, nasal symptoms, practical problems, non-hay fever symptoms.

Table 1 Laboratory characteristics of the studied patients

\begin{tabular}{lll}
\hline & Mean \pm SD & Range \\
\hline Hemoglobin & $11.37 \pm 0.56$ & $10.8-12.4$ \\
$\operatorname{lgE}$ & $171.29 \pm 197.86$ & $5-800$ \\
\hline
\end{tabular}


Table 2 Comparison of MIDA score before and after treatment among the studied patients

\begin{tabular}{|c|c|c|c|c|c|}
\hline & \multicolumn{2}{|c|}{ Before treatment } & \multicolumn{2}{|c|}{ After treatment } & \multirow{2}{*}{$\begin{array}{l}\mathrm{p} \\
\text { value }\end{array}$} \\
\hline & No. & $\%$ & No. & $\%$ & \\
\hline No pain I & 0 & $0 \%$ & 25 & $43.1 \%$ & $0.001^{*}$ \\
\hline Mild pain ॥ & 6 & $10.34 \%$ & 9 & $15.52 \%$ & 0.6 (NS) \\
\hline Moderate pain III & 44 & $75.86 \%$ & 19 & $32.76 \%$ & $0.001^{*}$ \\
\hline Sever pain IV & 8 & $13.79 \%$ & 5 & $8.62 \%$ & 0.6 (NS) \\
\hline
\end{tabular}

*Statistically significant difference. NS not statistically significant difference

We noticed here that IgE level in improved cases around 88.4 denote statistically significant difference within these group, whereas in not improved cases, there was statistically significant difference meaning high levels of IgE test in not improved cases.

\section{Discussion}

Rhinitis is defined as an inflammation of the lining of the nose and is characterized by nasal symptoms including anterior or posterior rhinorrhea, sneezing, and nasal blockage or itching of the nose. These symptoms occur during two or more consecutive days for more than $1 \mathrm{~h}$ on most days [11].

Allergic rhinitis is the most common form of noninfectious rhinitis and is associated with an IgE-mediated immune response against allergens. It is often associated with ocular symptoms [12].

Apart from local disease, allergic rhinitis can cause considerable morbidity including chronic sinusitis and otitis. The condition can also cause irritability and impaired sleep which can affect quality of life by leading to poor performance at school or work, absenteeism from school or work, and chronic tiredness. It can also have detrimental effects on emotional and social wellbeing [13].

Allergic rhinitis, in addition to having an adverse impact on the patient's quality of life, has potentially serious medical sequelae, including disturbed sleep, exacerbation of asthma, Eustachian tube dysfunction with otitis media, and rhinosinusitis [14, 15].

Migraine is a relatively severe form of headache occurring in attacks usually lasting between $4 \mathrm{~h}$ and 3 days, and with disabling accompanying phenomena such as nausea or vomiting, severe intolerance to light, sound, odors, and body movement [16].

Table 3 lgE level among studied patient according to patients' improvement

\begin{tabular}{lllll}
\hline & \multicolumn{2}{l}{ Patient improvement } & $\begin{array}{l}\boldsymbol{p} \\
\text { value }\end{array}$ \\
\cline { 2 - 4 } & Improved & Partially improved & Not improvement & \\
\hline $\operatorname{lgE}$ & $88.4 \pm 94.08^{\mathrm{a}}$ & $137.8 \pm 236.2^{\mathrm{ab}}$ & $270.2 \pm 224.1^{\mathrm{b}}$ & $0.003^{*}$ \\
\hline
\end{tabular}

*Statistically significant difference. ${ }^{a, b}$ Denote statistically significant difference within groups (post hoc analysis)
Rhinology setting, Perry et al. found that radiographynormal and endoscopy-normal headache patients had a $58 \%$ incidence of migraine [17].

The reasons for this correlation may be pathophysiological resemblance between these disorders. Different studies introduced immunologic mediators such as IgE (immunoglobulin E), histamine, tumor necrosis factor- $\alpha$ (TNF- $\alpha$ ), calcitonin gene-related peptide (CGRP), vasoactive intestinal peptide (VIP), D2 and F2 prostaglandins, interleukin-1 (IL-1), tryptase, and also activation of mast cells and secondary release of nitric oxide in both conditions $[18,19]$.

Migraines are a significant source of both medical costs and lost productivity. It has been estimated that they are the most costly neurological disorder [20].

With better but more expensive treatment options becoming available during the last $10-15$ years, migraine and other headache disorders has become the subject of considerable interest from the health economic and public health perspective [21].

Migraine and AR have many clinical similarities. It was seen that among patients with sinus headache referred to otolaryngology clinics, up to $75 \%$ may have histories compatible with the migraine criterion. Even in a tertiary care, Migraines are a significant source of both medical costs and lost productivity. It has been estimated that they are the most costly neurological disorder [20].

In our practice, we are seeing allergic rhinitis associated with migraine frequently, so we were dealing with selected patients having both allergic rhinitis and migraine.

In this study, we assessed ability of the treatment of allergic rhinitis in patients having migraine associated to decrease the attacks severity and frequency of their migraine.

In a study reported by Wheatley and Tobias (29 January 2015), as regard allergic rhinitis, most common between the ages of twenty and forty and that was close to our results [22].

As regards migraine, Lay and Bronner (May 2009) found that it affects slightly more boys than girls before puberty and two to three times more women than men after puberty [23]. And that agrees with our study in which females were more affected than males (about $63.79 \%)$.

In our study, $\mathrm{CBC}$ was done to exclude iron deficiency anemia as a cause of migraine (hemoglobin was found between 10.8 and $12.4 \mathrm{mg} / \mathrm{dl}$ ) that in a 2015 study in pain medicine. Also in a study by David Rosario, George observed that patients with higher levels of IgE (mean 373.75) had more severe headaches compared to those with lower levels of IgE (mean 3523), that agrees with our result. 


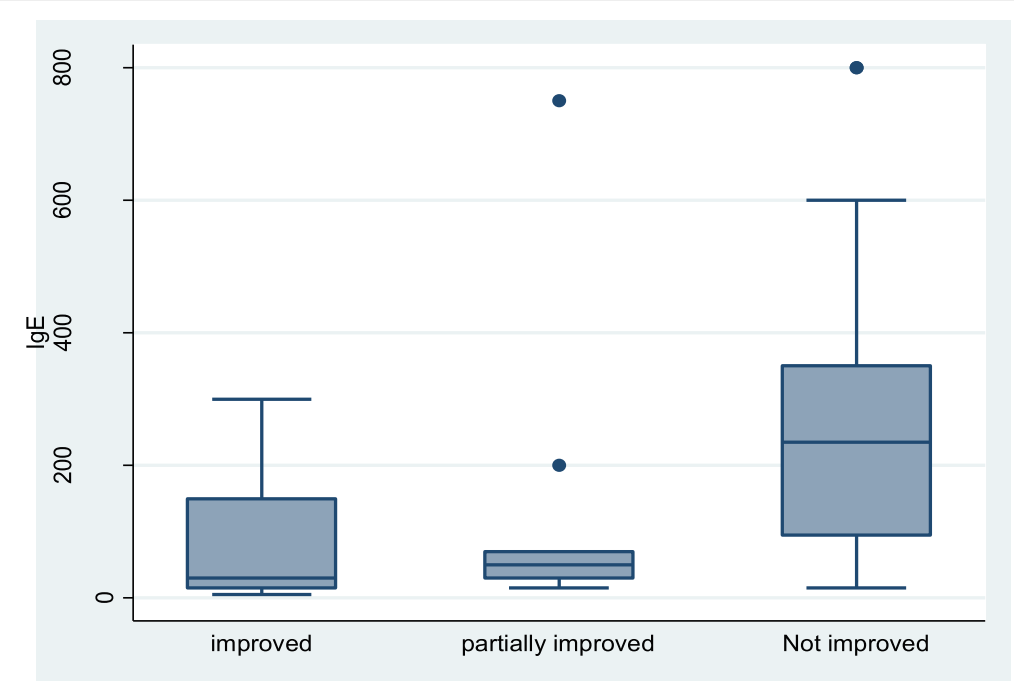

Fig. $1 \mathrm{lgE}$ level among studied patient according to patients' improvement

In a study reported by Barbee et al. in 1981, it says that mean total serum IgE levels were $38 \pm 43 \mathrm{KU} / \mathrm{l}-180 \mathrm{KU} /$ 1 in normal subjects and $94 \pm 93 \mathrm{KU} / \mathrm{l}$ in allergic subjects and asthmatics have higher mean IgE levels than those who are suffering from rhinitis [24]. That values agree with our result which showed that IgE levels were high in patients who had allergic rhinitis (mean IgE value was 171.29). Also in a study by David Rosario, George observed that patients with higher levels of IgE (mean 373.75) had more severe headaches compared to those with lower levels of IgE (mean 3523), that agree with our result showed that IgE test (mean 171.2 9) in patients have both allergic rhinitis and migraine $[25,26]$. In our study, IgE level among studied patient according to patients' improvement found to be improved $88.4 \pm 94.08$ statistically significant difference, partially improved $137.8 \pm 236.2$ denote statistically significant difference within groups (post hoc analysis), and not improvement $270.2 \pm 224(P$ value 10.003$)$ statistically significant difference.

Sanders et al. reported that spontaneous basophiles histamine release is increased in migraine patients. In fact, the pattern of this release is similar to the abnormal release patterns seen in patients with atopic dermatitis or food allergies. Twenty-even studies from several centers have suggested that food allergens interact with

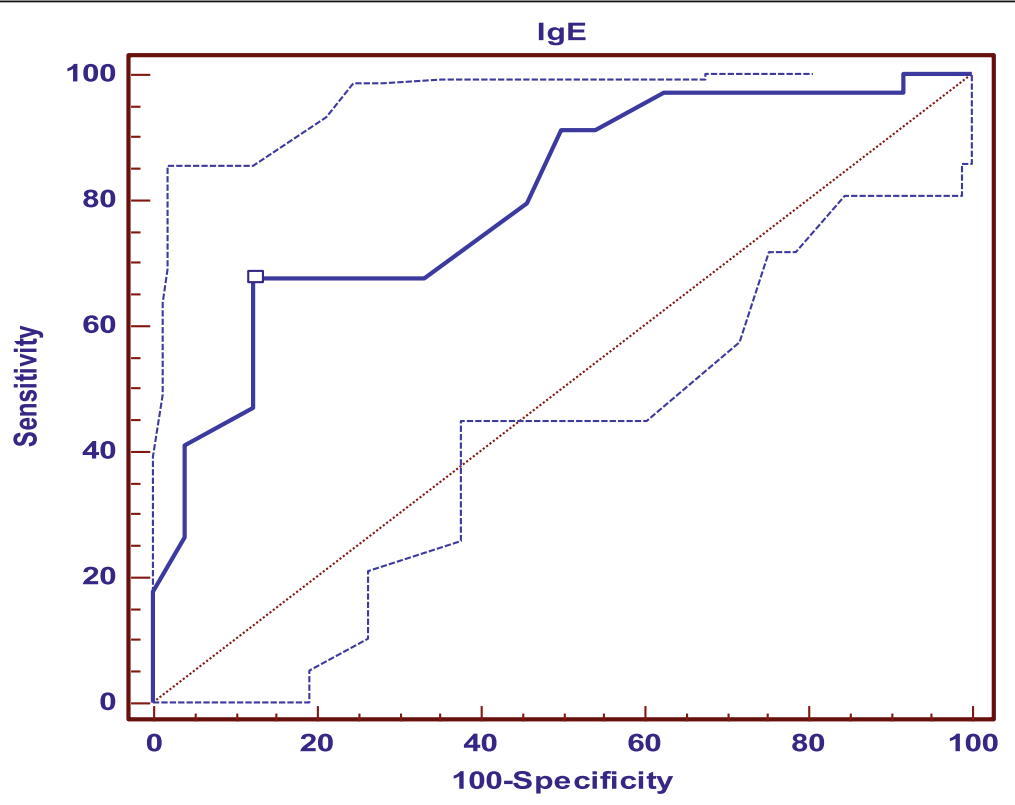

Fig. 2 ROC curve analysis of IgE to predict patient improvement with treatment 
Table 4 Quality of life assessment

\begin{tabular}{|c|c|c|c|c|}
\hline Parameter & Before treatment $(n=58)$ & After treatment $(n=58)$ & $x^{2}$ & $P$ value \\
\hline \multicolumn{5}{|l|}{ Sleep } \\
\hline Not troubled & $7(12.06 \%)$ & $32(55.17 \%)$ & & \\
\hline Moderately troubled & $40(68.96 \%)$ & $21(36.20 \%)$ & 32.34 & $<0.0001$ \\
\hline Extremely troubled & $11(18.96 \%)$ & $5(8.62 \%)$ & & * \\
\hline \multicolumn{5}{|c|}{ Non-hay fever symptoms } \\
\hline Not troubled & $4(18.96 \%)$ & $22(70.68 \%)$ & & \\
\hline Moderately troubled & $46(46.55 \%)$ & $29(15.51 \%)$ & 16.38 & $0.003^{*}$ \\
\hline Extremely troubled & $8(34.48 \%)$ & $7(13.79 \%)$ & & \\
\hline \multicolumn{5}{|l|}{ Practical problems } \\
\hline Not troubled & $15(25.86 \%)$ & $44(75.86 \%)$ & & \\
\hline Moderately troubled & $35(60.34 \%)$ & $11(18.96 \%)$ & 29.05 & $<0.0001$ \\
\hline Extremely troubled & $8(13.79 \%)$ & $3(5.17 \%)$ & & * \\
\hline \multicolumn{5}{|l|}{ Nasal symptoms } \\
\hline Not troubled & $5(8.62 \%)$ & 37 (63.79\%) & 38.22 & $<0.0001$ \\
\hline Moderately troubled & 31 (53.44\%) & $12(20.68 \%)$ & & * \\
\hline Extremely troubled & $22(37.93 \%)$ & $9(15.51 \%)$ & & \\
\hline \multicolumn{5}{|l|}{ Eye symptoms } \\
\hline Not troubled & $31(53.44 \%)$ & $45(77.58 \%)$ & & \\
\hline Moderately troubled & $22(37.93 \%)$ & $12(20.68 \%)$ & 8.18 & $0.014^{*}$ \\
\hline Extremely troubled & $5(8.62 \%)$ & $1(1.72 \%)$ & & \\
\hline
\end{tabular}

*Statistically significant $p<0.05$. McNemar chi-square test used

specific IgE on mast cells and basophils to cause the release of histamine, prostaglandins $\mathrm{D}$ and $\mathrm{E}$, and other vasoactive amines that cause vasodilatation and thus may provoke headaches [27]. That copes with our results which show $58.6 \%$ of patients improved by antihistaminic treatment.

A controlled clinical trial, in the Journal Article Somerville Bw The relief of acute migraine attacks with an analgesic/antihistamine combination containing paracetamol, codeine phosphate, doxylamine succinate, and caffeine (Mersyndol) compared with that achieved with a placebo, has been studied in a double-blind, crossover trial. Interest in intranasal (IN) administration as a noninvasive route for drug delivery continues to grow rapidly.

In our study, local steroids were used with antihistamines in treatment of allergic rhinitis, with observing their effect on migraine. The 2012 AAN guideline includes studies of histamines, antihistamines, and leukotriene receptor antagonists for migraine prevention. Three class II single-center studies (all from the same center) show the efficacy of histamine for migraine prevention, but in the other hand the role of the central histaminergic system in migraine is unexplored. At present, to predict the net effect of histamine in central networks seems quite impossible. However, both $\mathrm{H}_{3} \mathrm{R}$ and $\mathrm{H}_{4} \mathrm{R}$ ligands may theoretically have migraine prophylactic properties, but there seems to be a long and winding road before effective anti-histaminergic treatment against migraine is established. Despite being promising drug targets for several diseases, the lack of specificity and undesired side effects will probably be a major problem ongoing studies on $\mathrm{H} 3$ and $\mathrm{H} 4$ receptor $[28,29]$.

People who suffer from severe migraine want fastacting relief from the pain. When the medication is delivered intranasal-through the nostrils-relief can come in 15 to 30 min which is much faster than waiting for a pill to be dissolved, digested, and distributed throughout the body. This is especially true in the case of migraine.

Measurements of QOL and disabilities have emerged as important complementary approaches for the evaluation of the burden of headaches. Interest in research into the quality of life has been increasing over the last 20 years. But this field is still disregarded by some. However, it is now widely acknowledged that the personal burden of illness, as perceived by the patient, cannot be fully assessed by objective measures of disease severity, because for diseases such as asthma and allergic rhinitis, traditional clinical indices only moderately correlate with how patients feel and are able to function on a daily basis [30].

In our study, we categorized the patients according to MIDA score which was done before and after the treatment into 4 categories: grade I no pain $(0 \%)$, grade II 
mild pain (10.34\%), grade III moderate pain (75.86\%), grade IV sever pain $(13.79 \%)$ which showed obvious improvement after treatment of their allergic rhinitis by antihistaminic and steroids nasal spray as follow: grade I (43.1\%), grade II (15.52\%), grade III (32.76\%), grade IV (8.62\%). Patients on grade I (no disability) showing statistically significant difference being increasing in number, meaning more patients have no pain of migraine after allergic rhinitis treatment, and also patients on grade III (moderate disability) showing statistically significant difference before and after meaning more patients improved with overall percentage of patients' improvement according to MIDA score as follow: improved (43.1\%), partially improved (15.52\%), and patients show no improvement (41.38\%).

In our study, we categorized the patients according to MIDA score which was done before and after the treatment into 4 categories: grade I no pain $(0 \%)$, grade II mild pain (10.34\%), grade III moderate pain (75.86\%), and grade IV sever pain (13.79\%), which showed obvious improvement after treatment of their allergic rhinitis by antihistaminic and steroids nasal spray as follow: grade I (43.1\%), grade II (15.52\%), grade III (32.76\%), and grade IV (8.62\%). Patients on grade I (no disability) showing statistically significant difference being increasing in number.

Health-related quality of Life (HRQOL) has been considered an important variable to be managed in airway diseases.

In our study, there were significant improvements of patients QOL regarding sleep problems, nasal symptoms, practical problems, non-hay fever symptoms. Activities results also cope with MIDA score results.

In the study in Malaysia to compare QOL and disability between migraine sufferers and no migraine controls, the Malay versions of the WHOQOL-BREF and MIDAS questionnaires were easy to administer and can be completed quickly. No subjects had any difficulty using the instruments, indicating a high quality of the questionnaires. In this study, the overall perception score of QOL and health was significantly lower among migraine patients. This finding is consistent with those from other studies [31-33]. That reported a lower perception of QOL and health. The migraine sufferers had substantial and statistically significantly lower total QOL scores, physical health, and psychological health domain scores than the healthy control group. In another study conducted among migraine patients in the USA [34]. The total QOL, physical health, and social functioning scores of the migraine patients were substantially lower than the published norms [30].

In our study, there were significant improvements of patients QOL regarding sleep problems, nasal symptoms, practical problems, and non-hay fever symptoms. Activities result also cope with MIDA score results.

A similar study conducted among the Dutch population [34] reported diminished functioning and wellbeing among migraines. Consistently, total QOL, physical health, and psychological health scores were significantly lower among UK [35], French [36], Italian [37], and Indian [38] migraine patients than no migraine controls also cope with our results. All these studies agree with our results that there were significant improvement of patients health-related quality of life and MIDA score results after treatment of their allergic rhinitis and subsequent their migrainous attacks [39].

\section{Conclusion}

There is strong relation between migraine and allergic rhinitis, the use of intranasal corticosteroid sprays, and oral antihistaminic for 3 months for treatment of migraine associated with allergic rhinitis which led to decrease in the prevalence and frequency.

We found significant relation between IgE test and allergic rhinitis with migraine patients and recommend it in follow up.

Moreover, further studies with larger populations and longer duration are needed in order to determine the correlation between allergic rhinitis and migranous attack.

\section{Abbreviations}

CBC: Complete blood count; IGE: Immunoglobine E; ENT: Ear, nose, throat; AR: Allergic rhinitis; NO: Nitric oxide; MIADAS: Migraine disability assessment; ROC: Receiver operating curve; LR: Likelihood ratio; TNF: Tumor necrosis factor; CGRP: Calcitonin gene-related peptide; VIP: Vasoactive intestinal peptide; QOL: Quality of life

\section{Acknowledgements}

None.

Consent to participate

Written consent was obtained from all study participants and all participants included in the study have been informed about the procedures to be done and the expected results.

\section{Authors' contributions}

RZ analyzed and interpreted the patients' data regarding otorhinology examination and scoring system. DA collected the data, followed up patients, and printed the results. NI analyzed the statistical section and YT performed discussion and wrote the manuscript. All authors read and approved the final manuscript.

\section{Funding}

None.

\section{Availability of data and materials} Not applicable.

Ethics approval and consent to participate

Local ethics committee (Faculty of Medicine Suez Canal University under the number 321 date of approval-October 2017).

Consent for publication

Written consent for study publication was obtained from all study participants. 


\section{Competing interests}

The authors declare that they have no competing interests.

\section{Author details}

${ }^{1}$ Suez Canal University Hospitals, 4.5 Km Ring Road, Ismailia, Egypt. ${ }^{2}$ Insurance Hospital, Ismailia, Egypt.

Received: 11 December 2020 Accepted: 12 January 2021

Published online: 05 February 2021

\section{References}

1. Boes CJ, Capobianco DJ, Ctrer FM, Dodick DW, Garza I, Swanson JW (2008) Headache and other craniofacial pain. In: Bradley WG, Daroff RB, Fenichel GM, Jankovic J (eds) Neurology in clinical practice, 5th edn. ButterworthHeinemann, Philadelphia, PA, pp 2026-2042

2. Pawankar R, Canonica GW, ST Holgate ST, Lockey RF, Blaiss M. (2013) The WAO White Book on Allergy. Update. 122

3. Salo PM, Calatroni A, Gergen PJ, Hoppin JA, Sever ML, Jaramillo R, Arbes SJ, Zeldin DC (2011) Allergy-related outcomes in relation to serum IgE: results from the national health and nutrition examination survey 2005-2006. J Allergy Clin Immunol. 127:1226-1235

4. Martin VT, Taylor F, Gebhardt B (2011) Allergy and immunotherapy: Are they related to migraine headache? Headache 51:8-20

5. Mortimer JM, Kay J, Gawkrodger DJ (1993) The prevalence of headache and migraine in atopic children: an epidemiological study in general practice. Headache. 33(8):427-431

6. Shin JH, Kim BG, Kim SW, Cho JH, Park YJ, Kim SW. Immunomodulatory role of histamine $\mathrm{H} 2$ receptor in allergen-specific immunotherapy: a mouse model of allergic rhinitis. otolaryngol Head Neck Surg. 2011; 144(4):500-505.

7. Ku M, Silverman B, Prifti N, Ying W, Persaud Y, Schneider A. Prevalence of migraine headaches in patients with allergic rhinitis. Ann Allergy Asthma Immunol. 2006; 97(2):226-230. 53

8. Valet RS, Fahrenholz JM (2009) Allergic rhinitis: update on diagnosis. Consultant. 49:610-613

9. Sur DK, Scandale S (2010) Treatment of allergic rhinitis. Am Fam Physician. 81(12):1440-1446

10. Stewart WF, Lipton RB, Kolodner K (2003) Migraine disability assessment (MIDAS) score: relation to headache frequency, pain intensity, and headache symptoms. Headache 43(3):258-265

11. International consensus report on the diagnosis and management of rhinitis.Allergy. 1994; 49, 19: 1-34.

12. (1989) Immediate and late effects of hay fever. Post grad Med 85:183-190

13. American Academy of Allergy, Asthma, \&lmmunology. The Allergy Report. 2017; 142-143.

14. Corren J (2000) The link between allergic rhinitis and asthma, otitis media, sinusitis, and nasal polyps. Immunol Allergy Clin North Am. 20:445-460

15. (2014) International consensus report on the diagnosis and management of rhinitis. Allergy. 49:1-34

16. Berg. Economic evidence in migraine and other headaches: a review. Eur J Health Econ. 2004; 5: S43-S54.

17. Blumenthal HJ (2011) Headaches and sinus disease. Headache. 41:883-888

18. Schreiber CP, Cady RK, Billings C (2015) Is patient self-described "sinus" headache migraine? Neurology. S3:A311

19. Mennini, FS; Gitto, L; Martelletti, P. Improving care through health economics analyses: cost of illness and headache. The journal of headache and pain.2016; 9 (4): 199-206.

20. Stovner LJ, Zwart J-A, Hagen K, Terwindt G, Pascual J (2016) Epidemiology of headache in Europe. Eur J Neurol 13:333-345

21. Lipton RB, Diamond S, Reed M, Diamond ML, Stewart WF (2011) Migraine diagnosis and treatment: results of the American Migraine Study II. Headache. 41:638-645

22. Wheatley LM (2015) Togias. "Clinical practice. Allergic rhinitis". The New England Journal Of. Medicine. 372(5):456-463

23. Eross E, Dodick D, Eross M (2007) The sinus, allergy and migraine study. Headache 47:213-224

24. Aamodt AH, Stovner L, Langhammer A, Hagen K, Zwart JA (2017) Is headache related to asthma, hay fever, and chronic bronchitis? The HeadHUNT Study. Headache. 47:204-212

25. Mehle ME (2008) Allergy and migraine: is there a connection? Curr opiotolaryngol Head Neck Surg. 16:265-269
26. Rondón, C; Fernandez, J; Canto, G; Blanca, M (2010). "Local allergic rhinitis: Concept, clinical manifestations, and diagnostic approach" (PDF). Journal of investigational allergology \& clinical immunology.2015; 20 (5): 364-71; 371.

27. Ku M, Silverman B, Prifti N, Ying W, Persaud Y, Schneider A (2016) Prevalence of migraine headaches in patients with allergic rhinitis. Ann Allergy Asthma Immunol 97:226-230

28. Levy D, Burstein R, Strassman AM. Mast cell involvement in the pathophysiology of migraine headache: A hypothesis. Headache. 2016; 461:S13-S18.

29. Ku M, Silverman B, Prifti N, Ying W, Persaud Y, Schneider A (2006) Prevalence of migraine headaches in patients with allergic rhinitis. Ann Allergy Asthma Immunol. 97:226-230

30. Ro M-G, Isais-Millán R, Barreto-Vizcaíno S et al (2018) Subcutaneous histamine versus topiramate in migraine prophylaxis: a double-blind study. Eur Neurol 59(5):237-242

31. Guarsio G, Bertoli S, Cernetti R, Battistella PA, Setari M, Zacchello F (2013) Migraine and food int0lerance: controlled study in pediatric patients. Pediatr Med Chir 15:57-56

32. Babe KS, Serafin WE (2016) Histamine, bradykinin and their antagonists. In: Hardman JG, Limbird LE (eds) Goodman and Gilman's The Pharmacological Basis of Therapeutics, 9th edn. McGraw-Hill, Chicago, pp 581-600

33. Neubauer D, Kuhar M, Ravnik IM (1997) Antihistamine responsive cluster headache in a teen aged girl. Headache 57:296-298

34. Peatfield RC, Jarrett N, Glover V (2018) The pharmacology of food and drink. In: Sndler M, Ferrari M, Harnett S (eds) Migraine, Pharmacology and Genetics. Lippencott Williams \& Wilkins Pub, Philadelphia, pp 124-43(15)

35. Anselmi B, Targuini R, De Leeaordis $V$ et al (2017) Serum beta endorphin increase after intravenous histamine treatment in chronic daily headache. Recenti Prog Med 88:321-324

36. Valet RS, Fahrenholz JM (2009). "Allergic rhinitis: update on diagnosis". Consultant. 49: 610-3. Archived from the original. 2010-01-14.

37. Heatley RV, Denburg JA, Bayer N, Bienenstock J (2012) Increased plasma histamine level in migraine patients. Clin Allergy 12:142-149

38. Gastillo J, Martinez F, Corredera E, Lema M, Noya M (2015) Migraine and histamine: determining histidine in plasma and cerebrospinal fluid during migraine attacks. Rev Neurol 23:749-511

39. Holland S, Silberstein SD, Freitag F et al (2012) Evidence-based guideline update: NSAIDs and other complementary treatments for episodic migraine prevention in adults: report of the Quality Standards Subcommittee of the American Academy of Neurology and the American Headache Society. Neurology 78(17):1346-1353

\section{Publisher's Note}

Springer Nature remains neutral with regard to jurisdictional claims in published maps and institutional affiliations.

\section{Submit your manuscript to a SpringerOpen ${ }^{\circ}$ journal and benefit from:}

- Convenient online submission

- Rigorous peer review

- Open access: articles freely available online

- High visibility within the field

- Retaining the copyright to your article

Submit your next manuscript at $>$ springeropen.com 